Viviane Assunção

Universidade do Extremo Sul Catarinense, Criciúma, SC, Brasil

\title{
Migrantes por amor? Ciclo de vida, gênero e a decisão de migrar em diferentes fases da vida
}

\begin{abstract}
Resumo: Este artigo mostra a importância do curso de vida, entrelaçado à perspectiva de gênero, para analisar os processos de tomada de decisão de mulheres brasileiras sobre migrar (ou não) para a Holanda para viverem com seus companheiros holandeses. Segundo as interlocutoras de uma pesquisa etnográfica realizada entre 2012 e 2013, a idade é um importante fator a ser considerado para ponderar os riscos, vantagens e desvantagens da migração. Além da faixa etária, outros marcadores do curso de vida, como ter filhas/os, o nascimento das/os netas/os e a idade destes indivíduos também são considerados em suas decisões. O artigo também traz as considerações das interlocutoras da pesquisa sobre o amor, que, segundo elas, difere a cada fase da vida. Mais do que o amor por seus companheiros holandeses, elas evidenciam e reificam a idealização do amor materno.
\end{abstract}

Palavras-chave: migração; casamentos interculturais; ciclo de vida; faixa etária; gênero.

\section{(c) (7)}

Esta obra está sob licença Creative Commons.

\section{Introdução}

Venho lendo os diversos comentários aqui postados e como ando numa fase de muitos questionamentos, gostaria de saber a opinião de vocês... sei, que por um lado, a questão é muito pessoal, mas acho que vocês podem me dar alguma luz... Tenho 52 anos e uma vida relativamente estável no Brasil... Conheci meu namorado num site de relacionamento e estamos em contato há dois anos... Já estive na Holanda por duas vezes e tentei observar, comparar, enfim, analisar se seria mais interessante morar lá ou não... Tenho muitas dúvidas, porque não é fácil aprender um novo idioma, ter quer fazer um investimento de tempo e dinheiro, se adaptar a uma nova cultura, submeter-se aos testes, enfim, mudar totalmente de vida a essa altura... vocês 
1 Todos os nomes de minhas interlocutoras foram substituídos por nomes fictícios em respeito à sua privacidade.

\footnotetext{
2 Seguindo as críticas de Lucy Williams, penso que os termos casamento "misto" ou "intercultural" devem ser desprovidos do caráter essencialista, que implicaria o pertencimento dos indivíduos a um grupo como algo claramente delineado ou estático, ampliando sua concepção para contemplar as dinâmicas e intercâmbios socioculturais. Cf. WILLIANS, 2010.
}

poderiam falar um pouco de suas experiências para que eu possa ponderar melhor e ter mais coragem?

O texto acima foi postado por Maria, ${ }^{1}$ brasileira, em uma comunidade de uma rede social sobre brasileiros na Holanda. A página reúne dúvidas e comentários sobre a vida no país, tais como onde comprar produtos, eventos e novas leis de migração. Muitos desses comentários orientam brasileiras e brasileiros que foram para a Holanda para morar com um companheiro ou companheira. Informam, por exemplo, onde fazer cursos e testes de holandês ou conseguir documentos para viver legalmente no país europeu. O post de Maria recebeu cinquenta e sete comentários, que discorriam sobre amor, adaptação a um novo país e cultura, aprendizado de uma nova língua e inserção no mercado de trabalho. Nesses comentários, a faixa etária aparecia recorrentemente como um fator importante a ser ponderado nos processos de decisão sobre migrar ou permanecer em seu país de origem.

A bibliografia sobre casamentos mistos ou binacionais é bastante ampla. ${ }^{2}$ Os estudos tratam, mais recorrentemente, sobre as uniões entre homens do Norte e mulheres do Sul, e focam em diversos aspectos: mail order brides, agências matrimoniais, motivações para a procura de um cônjuge em outros países, ou, ainda, em suas relações com o turismo sexual. Mesmo que esses estudos falem sobre mulheres e homens de diferentes idades, não há uma problematização sobre as experiências distintas que indivíduos em diferentes fases de vida possam ter.

Neste texto, abordo o ciclo de vida como ferramenta analítica. Argumento que as experiências de vida são diferentes não apenas quando consideramos pessoas de contextos sociais e culturais distintos, como também sujeitos em diferentes etapas de vida. As expectativas e pressões sociais mudam de acordo com o ciclo de vida de cada indivíduo. Quando tratamos de casamentos mistos ou interculturais, de acordo com as interlocutoras de minha pesquisa, a idade é um fator importante para ponderar os riscos, vantagens e desvantagens de uma união que envolve a imigração para outro país. Interconectados à idade, fatores recorrentemente associados a marcadores de ciclos de vida, como o nascimento de filhos e netos, e suas respectivas idades, aparecem como elementos relevantes a serem considerados na decisão de migrar. Estes elementos são, por sua vez, perpassados por relações de gênero, que organizam dinâmicas familiares em cada estágio do ciclo de vida, como a tarefa do cuidado.

Outro ponto abordado por este artigo são as concepções das interlocutoras da pesquisa sobre o amor,

64 Estudos Feministas, Florianópolis, 24(1): 63-80, janeiro-abril/2016 
${ }^{3}$ ROCA GIRONA, Jordi, 2007.

4 Utilizo os termos "casamento" "relacionamento afetivo", assim como "maridos" e "namorados", obedecendo às informações dadas por minhas interlocutoras. Segundo elas, os holandese apenas se consideram "maridos" se houver o casamento oficia (religioso e/ou civil). Caso contrário, os cônjuges tratam-se como namorados. que também é significado de forma diferente a cada etapa da vida. Além das noções sobre amor contingente (em oposição ao amor romântico), as mulheres brasileiras reificam a idealização do amor materno. Para as interlocutoras da pesquisa, o amor da mãe pelos filhos se sobrepõe ao amor pelos companheiros, pois este sentimento seria imutável e superior aos demais. Neste sentido, podemos problematizar a definição dada a essas mulheres, que já foram denominadas "migrantes por amor", ${ }^{3}$ por migrarem para irem viver com seus parceiros amorosos.

\section{O contexto da pesquisa}

Os dados aqui apresentados são resultados de uma pesquisa etnográfica realizada na Holanda, entre 2012 e 2013 , com mulheres brasileiras casadas ou em relacionamento afetivo com homens holandeses. ${ }^{4}$ Todas as mulheres entrevistadas, no total de 15, viviam na Holanda com seus companheiros. Realizei conversas informais, algumas delas gravadas, e convivi com algumas dessas mulheres, totalizando cerca de trinta interlocutoras. Com algumas delas, foi possível, também, conversar com seus maridos ou namorados e participar de momentos de intimidade familiar, como festas e refeições com os filhos. Além disso, utilizei as redes sociais como forma de contato com algumas interlocutoras. As questões e comentários que postavam nessas redes serviram-me de fontes de informação sobre os temas que eram mais relevantes no cotidiano dessas mulheres na Holanda, que vão desde onde comprar feijão ou requeijão até o ensino de português aos filhos nascidos na Europa.

As interlocutoras de minha pesquisa são provenientes de diferentes estados brasileiros (Ceará, Bahia, Espírito Santo, Santa Catarina, Rio Grande do Sul, Minas Gerais, Distrito Federal, Goiás e São Paulo), idades (variando de 22 a 64 anos) e classes sociais. Elas conheceram seus companheiros também de diferentes formas: no Brasil, quando os holandeses vieram a negócios ou em férias; pela Internet, por meio de redes sociais ou sites de relacionamento; outras migraram para a Holanda indocumentadas e conheceram seus companheiros no país. Nos dois primeiros casos, ocorreram visitas do atual companheiro no Brasil e, também, idas da brasileira à Holanda e a manutenção de um relacionamento a distância em um período que pode variar entre um e três anos até a decisão da mudança da mulher para o país europeu.

De acordo com o IND (Serviço de Imigração e Naturalização dos Países Baixos), há, atualmente, 16 mil brasileiros vivendo legalmente na Holanda, sendo que a maioria são mulheres e foram para o país por motivo de 
${ }^{5} \mathrm{Em} \mathrm{2001}$, entrou em vigor a 'Vreemdelingenwet 2000'(VW 2000), que trouxe mudanças na concessão de refúgio e asilo. De acordo com Focus Migration [s.d.], outro objetivo desta lei foi desestimular a migração para formação familiar, e evitar os "falsos casamentos", que ocorreriam como estratégia para conferir status lega a um dos parceiros interessados em migrar para trabalhar na Holanda, principalmente imigrantes provenientes da Turquia e do Marrocos. ${ }^{6}$ A lei exclui a obrigatoriedade de visto e aprovação em testes de cidadãos da Austrália, Canadá, países da União Europeia, Japão, Mônaco, Nova Zelândia, Estados Unidos, Coréia do Sul, Suíça e Vaticano. O Migrant Integration Policy Index (2007) considera que a Holanda apresenta condições desfavoráveis para reunificação familiar devido aos critérios de eligibilidade.

7 De acordo com BruquetasCallejo et al. (2009), esta política migratória, aprovada em 2005 incorpora a ideia dominante de que a migração da família é uma ameaça à integração desses sujeitos na sociedade holandesa. ${ }^{8}$ SANTOS, Marta, 2012; TOGNI, 2008; ASSIS, Glaucia, 2011 PISCITELLI, Adriana, 2011; ROCA GIRONA, Jordi, 2007, 2010; ROCA GIRONA et al., 2009; RITTINER, Maria Eduarda, 2010.

9 SCHAEFFER-GRABIEL, Felicity, 2004; ROCA GIRONA, 2011 ; THAI, HUNGCAM, 2002, 2008.

${ }^{10}$ PISCITELLI, 2010.

\author{
" PISCITELLI, 2011. \\ ${ }^{12}$ BLANCHETTE, 2005. \\ ${ }^{13}$ BOURDIEU, 1972.
}

${ }^{14}$ WOORTMANN, 2004. reunificação familiar. Desde o início do século XXI, o governo holandês vem adotando medidas ${ }^{5}$ que dificultam a aquisição de visto para mulheres ou homens provenientes de países "em desenvolvimento" que desejam ir para a Holanda para viver com seus companheiros. ${ }^{6} \mathrm{~A}$ partir de 2005 , para conseguir o visto, esses indivíduos necessitam ser aprovados em exames de língua e cultura holandesa realizados em consulados holandeses em seus países de origem. ${ }^{7}$ Além disso, o cidadão holandês deve possuir residência fixa e comprovar renda suficiente. Após migrarem, os/as parceiros/ as estrangeiros/as devem estudar holandês e só adquirem visto permanente após três anos de relacionamento. Em 2012, o Decreto de Integração Civil (Bes/uitInburgering) passou a obrigar os casais a se casarem oficialmente no país de origem do estrangeiro antes de migrar.

\section{Casamentos interculturais, gênero e ciclo de vida}

As uniões entre mulheres brasileiras e homens europeus começaram a chamar a atenção de pesquisadores principalmente a partir do ano $2000 .{ }^{8} \mathrm{Em}$ alguns aspectos, tais como os processos de adaptação e as motivações para procurar um cônjuge estrangeiro, estes estudos podem ser semelhantes a outros que focam em relacionamentos afetivos entre homens europeus ou estadunidenses e mulheres asiáticas, eslavas e latinas. ${ }^{9}$

Adriana Piscitelli ${ }^{10}$ critica alguns estudos europeus sobre casamentos mistos que afirmam que muitas dessas uniões - sobretudo as por conveniência, forçadas e de reunificação familiar - seriam perigosas para as mulheres, pois estas estariam propensas à violência doméstica e exploração sexual. Esses estudos, considera a antropóloga, seriam ingênuos e etnocêntricos por considerarem a total separação entre afetos e interesses, e conceberem pouca agência das mulheres provenientes de países pobres.

Em concordância com essas observações, minha pesquisa toma como ponto de partida a intersecção entre afetos e interesses, dissolvendo a dicotomia entre "casamento por amor" e "casamento por interesse", ou "casamento por papéis". Como apontado por Piscitelli, ${ }^{11}$ há relações entre afetos, interesses e dinheiro. Em outras palavras, podemos considerar, como sugerido por Thaddeus Blanchette, ${ }^{12}$ que todo casamento envolve interesses. O casamento, pensado a partir da obra de Pierre Bourdieu, ${ }^{13}$ pode ser visto como uma estratégia de reprodução social. Para o sociólogo francês, os casamentos se realizam em um campo de jogo e envolvem riscos. De acordo com essa perspectiva, como explica Klaas Woortmann, ${ }^{14} \mathrm{O}$ "sucesso nesse jogo depende 
15 WOORTMANN, 2004.

${ }^{16}$ CONSTABLE, Nicole, 1998. Observo que essas divisões entre Norte e Sul não são apenas geográficas, mas compreendem, também, $e$ principalmente, conotações socioculturais, econômicas e políticas. ${ }^{17}$ MANDERSON, Lenore e JOLLY, Margaret, 1997.

${ }^{18}$ PFLUGFELDER, 1999.

19 YOUNG, 2005.

${ }^{20}$ PISCITELLI, 2010; GREGORIO GIL, Carmen, 2002; ROSALDO Michelle e LAMPHERE, Louise, 1974.

${ }^{21}$ PISCITELLI, 2009.

22 HONDAGNEU-SOTELO, 2004. da habilidade de quem joga". Neste sentido, é importante pensar que existem as boas e as más alianças, ${ }^{15}$ para levar em conta as uniões bem e malsucedidas, tomando como ponto de partida as expectativas dos parceiros e como estes significam o sucesso (ou não) de uma relação.

Tais uniões são especialmente interessantes para acadêmicos porque as escolhas dos parceiros não são aleatórias, sem referências à classe, gênero, nacionalidade ou etnicidade. Ao contrário, eles seriam marriage-scapes, configurados e limitados por fatores sociais, econômicos, políticos e culturais. Estes marriage-scapes refletem também certos padrões generificados. Dessa forma, as uniões ocorrem, em maior frequência, entre mulheres de países pobres do sul e homens de países ricos do norte. ${ }^{16}$

Além desses padrões, como mostra Gregory Pflugfelder, ${ }^{17}$ há também "geografias de desejo", ${ }^{18}$ ou lugares de desejo formados por confluências entre culturas e intercâmbio, ao invés de um fluxo unidirecional de poder e desejo. Robert Young ${ }^{19}$ lembra que os desejos dos brancos europeus pelos "Outros" provenientes das periferias do globo também estão atrelados à história do colonialismo e do imperialismo. Neste sentido, o desejo não pode ser visto de forma essencializada, mas como produto de relações históricas, hierárquicas e desiguais.

Ao considerar essas uniões, devemos, também, atentar para as imagens construídas e enraizadas sobre as mulheres "não ocidentais", principalmente eslavas, asiáticas e latinas, que incluem as mulheres brasileiras. Se, por um lado, as representações dessas mulheres estão associadas à natureza (em oposição à cultura), o que as caracteriza como irracionais, mais emotivas e sensuais, por outro, relacionam-as à domesticidade, com características de passividade, maternidade, submissão e especial habilidade para as tarefas de cuidado. ${ }^{20}$ Como aponta Piscitelli, ${ }^{21}$ as representações sexualizadas das mulheres brasileiras também podem levar a um empoderamento dessas mulheres. Ao interiorizarem e positivarem a sensualidade e sexualidade a elas associadas, às mulheres é possível, ainda, utilizar esses atributos a seu favor, como forma de capital que lhes pode proporcionar ascensão social. Neste sentido, sua beleza e juventude física lhes garantem um sentimento de superioridade em relação às mulheres europeias, o que foi corroborado pelas observações de minhas interlocutoras sobre as mulheres holandesas.

As representações sobre os sujeitos que se engajam em relacionamentos interculturais também são perpassadas por noções de gênero. Pierrette Hondagneu-Sotelo ${ }^{22}$ observa que a categoria gênero não pode ser tomada apenas como variável, mas como um conjunto de relações que organizam os padrões dos processos migratórios. Deste modo, torna-se 
${ }^{23}$ PESSAR e MAHLER, 2001.

${ }^{24}$ PISCITELLI, 2003.

${ }^{25}$ ROCA GIRONA, 2007.

${ }^{26}$ BOURDIEU, 2004

${ }^{27}$ MOTTA, Alda, 1999, p. 205.

${ }^{28}$ PAIS, 2009.

29009. importante o conceito de "geografias generificadas de poder", ${ }^{23}$ desenvolvido por Patricia Pessar e Sarah Mahler, que permite analisar as relações de gênero em contextos transnacionais. De acordo com as autoras, em múltiplas escalas sociais e espaciais que atravessam os territórios transnacionais, as relações de gênero podem ser reafirmadas ou reconfiguradas. Através dessas geografias generificadas de poder, os sujeitos são localizados socialmente, dentro de relações desiguais e hierárquicas. Essas diversas posições, segundo Piscitelli, ${ }^{24}$ possibilitam diferentes agências, entendidas em seus aspectos cognitivos, que envolvem tanto imaginação, planejamento e estratégias, quanto práticas concretas.

Em pesquisa realizada com homens espanhóis casados com mulheres latinas ou eslavas, Roca Girona ${ }^{25}$ mostra que os perfis de homens e mulheres são muito mais heterogêneos do que os discursos de senso comum apontam. Ele argumenta que o senso comum descreve as mulheres como jovens que estão procurando uma oportunidade de fugir da pobreza em seus países de origem e homens incapazes de cumprirem as exigências das mulheres locais. Como aponta o comentário de Maria no início deste artigo, não apenas mulheres jovens, como também mulheres com mais de quarenta anos e com situação econômica estável iniciam relacionamentos com homens europeus e podem experienciar a migração nesta fase da vida. A idade, segundo Maria e outras interlocutoras, influencia as decisões das mulheres da pesquisa sobre migrar.

A idade é aqui considerada, seguindo as observações de Bourdieu, ${ }^{26}$ como um fator biológico manipulado e manipulável socialmente. Apesar de ser expresso pela idade, o tempo é socialmente construído, e adquire significado social como grupos de idade - jovens, adultos, velhos - ou como legitimidades para realizar determinadas práticas sociais. $^{27}$

A idade de um indivíduo não é mais visibilizada por determinados marcadores de ciclo de vida, como casamento, filhos ou ingresso no mercado de trabalho. Autores como José Machado Pais, ${ }^{28}$ por exemplo, acreditam que as fronteiras entre as gerações estão cada vez mais fluidas, e observam que as trajetórias da vida adulta também podem ser reversíveis, como as mudanças de empregado para desempregado, ou, ainda, de casado para divorciado, o que pode levar os adultos a voltarem para a casa dos pais, ou, nas palavras de Pais, ${ }^{29}$ para uma condição juvenil. Se antes o casamento ou a obtenção de trabalho poderiam conferir o status de vida adulta, atualmente não há mais ritos de passagem que delimitam as fases da vida de forma precisa. 
302010

${ }^{31}$ DEBERT, 2010.

32 DEBERT, 2010.

${ }^{33}$ MOTTA, 2006.

${ }^{34}$ SCOTT, 2002

35 DEBERT, 2010.

36 DEBERT, 2010.

Esta desestabilização das fases da vida também está relacionada a novos valores culturais. De acordo com Guita Debert, ${ }^{30}$ a juventude pode ser pensada como um valor em oposição à velhice. A juventude não está mais associada a uma faixa etária específica, pois se acredita que é possível conquistá-la através do engajamento em práticas de consumo e serviços específicos. Em contraste, a velhice passou a representar negligência com o próprio corpo e falta de motivação para a vida. Neste sentido, há uma radicalização dos processos de construção das fases da vida, que leva a novas hierarquias sociais. Estas etapas da vida estão relacionadas a escolhas individuais próprias da sociedade de consumo e da modernidade. ${ }^{31}$

Segundo Debert, ${ }^{32}$ na esfera familiar, há, nos dias de hoje, uma grande variedade de idades de eventos demográficos, como casamentos, divórcios ou nascimento dos filhos. Isto produz gerações com variedades de idades cronológicas. Mais do que uma sequência cronológica, a idade expressa, contemporaneamente, modos de ser e de estar no mundo. ${ }^{33}$ Parry Scott, ${ }^{34}$ por exemplo, mostra como mulheres de cinquenta anos oscilam entre os polos do envelhecimento e da juvenilização. São "idosas jovens", que participam de grupos de Terceira ldade, e expressam a alegria relacionada aos mais jovens. Por outro lado, mães adolescentes buscam uma "adultização" precoce para serem melhores aceitas em seu meio social.

Apesar da maior flexibilização das etapas do ciclo de vida, a idade cronológica não deixou de ser uma variável importante na sociedade contemporânea, na organização social e definição de status de indivíduos. Há comportamentos apropriados, direitos e deveres que estão relacionados a cada faixa etária, que está "acompanhada da transformação das idades num laço simbólico privilegiado para a constituição de atores políticos e redefinição de mercados de consumo". ${ }^{35}$ Como observa Debert, ${ }^{36}$ o curso da vida como construção social e cultural não pode ser entendido como algo que os seres humanos podem fazer e refazer, um processo que não impõe limites à criatividade e ao qual qualquer sentido pode ser atribuído.

Ressalto que, assim como as relações de gênero são elementos estruturantes nos processos migratórios, também são estruturantes nas diferentes etapas do ciclo de vida dos sujeitos. O gênero organiza as dinâmicas familiares e configura os diferentes papéis que os indivíduos assumem em cada estágio de suas trajetórias. A seguir, mostro como marcadores do ciclo de vida, como ter filhos e o nascimento dos netos, relacionados também à idade cronológica, interferem no processo de decisão das interlocutoras de minha pesquisa sobre migrar, permanecer na Holanda ou retornar para o Brasil. 


\section{Os filhos (e netos)}

Entre minhas interlocutoras, a decisão de ter um filho com o companheiro holandês coincidia com a decisão de estabelecer-se na Holanda de forma definitiva, ou, pelo menos, até que a criança completasse 18 anos. Elas argumentavam sobre a qualidade do ensino holandês e sobre as meIhores condições de vida para criar uma criança na Holanda. Mas, também, concordavam que, caso separassem de seus companheiros, dificilmente conseguiriam autorização do pai de seus filhos para morar com eles no Brasil. Segundo elas, os homens holandeses são mais participativos no cuidado dos filhos do que os homens brasileiros, e raramente consentiriam que o filho fosse morar com a mãe em outro país.

[...] os holandeses não querem que o filho vá ser criado em outro país, em um país de terceiro mundo. O meu marido já disse: se eu morrer, e a gente tiver um filho, você vende a casa e tudo, mas... [não volte para o Brasil] (Silvia, 37 anos).

Se você tem um filho, pesa muito. Porque é o sistema deles, eles não vão permitir outra coisa. Aqui não é como no Brasil que os homens não querem a guarda. Aqui não. Eles lutam pela guarda do filho. [...] Aqui, quando eles querem ser pais, eles são pais indo e voltando. Não é só ser pai para coisa material, para comprar um filho, como acontece no Brasil, infelizmente. Aqui pai e mãe são pai e mãe (Sara, 24 anos).

Ter ou não filhos também é um dos fatores que impactam na decisão sobre morar ou não na Europa com o companheiro holandês. Janete, que mora há oito anos na Holanda, tinha 36 anos quando conheceu o atual marido pela Internet. Recém-divorciada, viajou para alguns países europeus, inclusive a Holanda, onde conheceu pessoalmente o companheiro com quem mantinha amizade pela Internet. Ela contou que se apaixonou por ele quando o viu. A decisão de migrar para viver com o companheiro ocorreu após avaliar sua atual condição e a do atual companheiro. Segundo ela, "aos 30 e poucos anos, você não vai mudar sua vida completamente, né". Janete acredita que o fato de não ter tido filhos facilitou a decisão.

Entretanto, algumas mulheres que migraram com filhos do casamento anterior elogiavam os homens holandeses por criarem os filhos de suas companheiras "como se fossem seus filhos de sangue". Além de descreverem as atitudes dos homens holandeses como "não machistas", em contraste com os homens brasileiros, elas destacaram as melhores oportunidades de ensino e futuro que teriam morando na Europa. Apesar de terem casamentos bem-sucedidos entre holande-

70 Estudos Feministas, Florianópolis, 24(1): 63-80, janeiro-abril/2016 
ses e brasileiras, cujos filhos foram bem recebidos pelos maridos, há casos em que ter filhos pode dificultar o rompimento de relacionamentos violentos ou malsucedidos.

Isso porque, para permanecer de forma legal no país, o cônjuge estrangeiro depende legalmente do cidadão holandês para manter seu visto nos três primeiros anos de relacionamento. Os filhos que acompanham as mães no exterior também são dependentes do homem holandês pelo mesmo período. Denise mudou-se para a Holanda com os dois filhos adolescentes para morar com o namorado. Após meses de relacionamento, o companheiro começou a ter problemas de alcoolismo e a ser violento com ela. Ele ameaçava contar à polícia que não estavam mais juntos, o que a levaria a perder o visto provisório. Ela contou que, após alguns anos, o fato de os filhos terem se mudado para viverem sozinhos e a ter uma vida mais independente possibilitou que ela terminasse a relação.

O papel dos filhos, portanto, é ambivalente nesses relacionamentos. Por um lado, não tê-los torna a decisão de migrar mais fácil. Por outro, o relacionamento com homens holandeses aparece nos discursos como forma de oportunizar um futuro melhor para os filhos. Algumas de minhas interlocutoras com mais de cinquenta anos já tinham filhos adultos vivendo no Brasil. É o caso, também, de Maria, cujo comentário está no início deste artigo. Ela explica que tem uma filha, que estuda Medicina e mora com ela: "sou 'empreguete' dela". A filha pretende se casar no ano seguinte, o que significaria uma nova etapa na vida da mãe.

Já Marta resolveu migrar pela segunda vez para a Holanda após o casamento da filha. Na primeira vez, era recém-separada e deixou-a com uma prima. Seu objetivo era pagar a faculdade da filha. Trabalhou como faxineira por cinco anos, conseguiu pagar os estudos e comprar um pequeno apartamento no Brasil. Voltou para o Brasil e, quando acabou $o$ dinheiro que tinha guardado, migrou para os Estados Unidos, onde ficou por três anos. Voltou ao Brasil para o casamento da filha, que foi morar no apartamento da mãe com o marido. Marta, sem dinheiro, resolveu migrar novamente para a Holanda. Lá, conheceu seu namorado holandês. Ela disse que este relacionamento a fez passar doze anos fora do Brasil. Quando a entrevistei, ela tinha decidido voltar, por saudades da filha e neta, recém-nascida.

Mas na minha cabeça, eu, ficando legal, trabalharia, e conseguiria, mais a miúdo, ver minha filha. Ao invés de uma vez por ano, eu poderia ir mais vezes e ela vir. Mas isso não acontece. Porque depois da papelada, você vê que tudo aquilo que você imaginou não é real. E o que aconteceu: eu nem abracei a Holanda, nem abracei o Brasil. Eu fiquei no meio. E ficar dividida 
${ }^{37}$ ATTIAS-DONFUT, Claudine, 1995.

${ }^{38} 2006$

${ }^{39}$ MOTTA, 2006 é a pior coisa que pode te acontecer. Eu não recomendo. Eu acho que se a pessoa pensa em sair do país dela para ir para outro, ela tem que pensar com a razão, pensar muito bem. Porque ou ela abraça o país novo, se legaliza, trabalha, tem uma vida normal... Agora eu tenho isso aqui, mas não tenho minha família, não tenho minha filha, não tenho minha neta aqui. Então é uma tortura que tem dentro de mim. [...] Isso muda de pessoa para pessoa. Eu sou mãemãe, eu sou vó, vó mesmo. Eu tenho um sentimento de mãe, eu tenho um sentimento de vó. $E$ está sufocante.

Marta estava decidida a deixar o companheiro e mudar-se para o Brasil. Seus planos eram cuidar da neta enquanto a filha trabalha, e, no futuro, conseguir um emprego. No entanto, ela sabia das dificuldades em voltar a trabalhar aos 56 anos e após doze anos fora do mercado de trabalho no Brasil.

Gente, eu já tenho 56. [...] Eu não tenho nada contra a minha idade não, viu? Eu acho que eu tô muito bem, muito melhor que muita gente aos 20 anos. Mas o que está pegando é que eu estou vendo os anos passarem, e eu quero aproveitar minha neta e minha filha enquanto eu estou de pé e com energia para andar, para brincar, enquanto eu estou bem disposta e não quando eu estiver doente e em uma cama.

Marta tomou a decisão de voltar ao Brasil para ficar mais perto da filha e da neta após anos de frustração na Holanda. Morando lá legalmente devido ao relacionamento com um holandês, ela esperava ir e voltar do Brasil com frequência. Entretanto, ainda trabalhava ilegalmente, como faxineira, e seus ganhos eram insuficientes para tantas viagens. Ela admite que seu marido "tem uma parcela de culpa" nesta frustração.

A exemplo de Marta e Maria, mulheres em torno dos 50 anos têm sido denominadas como geração intermediária, ou geração pivô. ${ }^{37}$ Mais do que a faixa etária, o termo é usado para descrever particularmente as mulheres que realizam trabalho de apoio a outras gerações: tanto pais, que se tornam menos independentes com a idade avançada, quanto os netos. Motta ${ }^{38}$ lembra que a definição da geração pivô é relacional e situacional. A autora explica que as idades de intermediação e apoio constante entre gerações variam, entre outros fatores, de acordo com o dinamismo das relações do grupo de parentesco. A autora lembra que a solidariedade entre as gerações ocorre, em boa parte, graças ao trabalho não remunerado e esforço emocional realizado pelas migrantes. "Realmente não dá para pensar a geração pivô sem pensar no cuidado, no apoio e no papel fundamental das mulheres nele". ${ }^{39}$ Essas

72 Estudos Feministas, Florianópolis, 24(1): 63-80, janeiro-abril/2016 
${ }^{40}$ CHAUfFAUT, Delphine, 2001

${ }^{41}$ MOTTA, 2006. mulheres apresentam uma espécie de "especialização familiar" para as atividades de cuidado e são um vetor fundamental de coesão entre os membros de uma mesma família. ${ }^{40}$ Além de resultar de um aumento na expectativa de vida, a geração pivô também resulta de fatores econômicos e políticos da sociedade contemporânea, como desemprego ou precariedade do emprego; por dissolução do casamento; ou, ainda, pelo fato de os mais velhos terem casa própria ou proventos de aposentadorias ou pensões que são partilhadas, apesar de serem, em muitos casos, escassas. ${ }^{41}$ Este parece ser o caso de Marta, que, com o nascimento da neta, foi reinserida na tarefa de cuidado, apoiando a filha enquanto esta trabalha, e de Maria, que considera a possibilidade de migração após o casamento da filha.

Ir e vir do Brasil foi o conselho dado a Maria por outros membros da comunidade onde sua dúvida foi postada. Segundo algumas mulheres, esta seria a solução para conviver com a distância dos filhos, netos e parentes que deixaram em seu país de origem. Andrea vive há treze anos na Holanda, e aconselhou Maria a "não se desfazer de nada do que tem no Brasil", como casa e planos de saúde. Em entrevista, ela me disse que sabia que conseguir emprego na Holanda aos 43 anos sem nunca ter trabalhado no país e nem dominar o idioma não seria fácil. Por isso, não tentou, nem se submeteria a trabalhos geralmente feitos por imigrantes com pouca qualificação, como limpeza: "quem é acostumada a trabalhar com o intelecto dificilmente aceitará qualquer coisa", ela postou em uma rede social. Andrea era coordenadora de uma escola no Brasil, e, após algum tempo na Holanda, criou uma página na Internet para dar informações para os brasileiros que vivem no país.

No entanto, nem todas as mulheres podem ir e voltar para o Brasil com frequência, como Marta. E esta foi a advertência de outros membros da comunidade para Maria. As frequentes viagens têm um alto custo. Por isso, os conselhos para "criar raízes" e "ter uma ocupação", mesmo não remunerada. As dificuldades em aprender o novo idioma e conseguir um emprego eram algo com que todas concordavam, e estavam justificadas pela idade. Segundo Ester, a situação é diferente para quem migra aos vinte anos e tem filhos em outro país, como ela própria, que mora há vinte e cinco anos na Holanda com o marido e os filhos.

Concordo plenamente que na nossa idade (também tenho 52), a coisa é bem diferente! Quem é jovem e vem com a intenção de formar família, cria laços, tem que se adaptar na marra, às vezes, por causa das crianças. Já quem vem só pra ficar com o namorado, precisa ter uma rotina de trabalho, seja ele qual for (Celina). 
Os vinte anos são caracterizados pelas interlocutoras como a idade da aventura, da coragem e dos riscos. Já, aos cinquenta anos, a mulher precisaria "analisar com realismo", segundo os conselhos de outras brasileiras. Isto inclui não apenas uma oposição entre razão e emoção, como, também, noções e expectativas sobre relacionamentos e amor.

\section{Do amor confluente ao amor materno}

Amor é lindo, mas certamente a paixão passa, se a gente dá sorte fica o companheirismo e muitas outras coisas boas, mas nada disso - por mais importante que seja - constitui um pacote suficiente para justificar uma mudança de vida tão radical (Gisele, há dez anos na Holanda).

Esta declaração de Gisele vai ao encontro de outras declarações que aconselham Maria a "pensar racionalmente" sobre o relacionamento. São subjacentes a este e outros discursos de minhas interlocutoras as ideias de amor finito, em oposição a um ideal de amor romântico, que seria eterno. Também surgem as noções de independência dos parceiros e a necessidade, também, de criar um círculo social e atividades independentes do marido.

A independência financeira, como já apontada anteriormente, é difícil para essas mulheres, especialmente aquelas que migraram com mais de quarenta ou cinquenta anos. No entanto, as mulheres que encontrei na Holanda conseguem ter vida social independente do marido, principalmente com outros brasileiros. Para isso, utilizam a Internet (como websites, blogs e redes sociais) e frequentam lugares de sociabilidade de imigrantes, como as Igrejas. As redes de amizade fornecem informações importantes sobre a vida holandesa e a adaptação no país, na mesma medida em que oferecem apoio emocional para lidar com a distância do Brasil.

É interessante observar que a ideia de ter uma vida social ativa é considerada por minhas interlocutoras como uma das condições para manter o relacionamento feliz. Por essa razão, Mônica foi criticada quando afirmou, em resposta à dúvida de Maria, que "por amor, vale a pena". Algumas mulheres argumentam que o amor não seria suficiente para tomar a decisão de migrar, e atentam para as mudanças que o amor pode ter com o passar dos anos.

O primeiro AMOR deve ser por nós mesmas, tomar decisão por AMOR a outra pessoa acarreta em muitas coisas. A primeira delas pode ser a decepção e depois o arrependimento... Amar é bom, ser amado também é, se o amor pode trazer alguém até aqui, este mesmo amor pode levar alguém até lá... [...] Eu gosto de amar e ser amada, mas chega uma altura na

74 Estudos Feministas, Florianópolis, 24(1): 63-80, janeiro-abril/2016 
${ }^{42}$ BONZON, Michel, 2005.

${ }^{43}$ BEALL, Anne e STERNBERG, Robert, 1995.

${ }^{44}$ COSTA, 1998.

${ }^{45}$ AZEVEDO, Thales, 1981.

${ }^{46}$ GIDDENS, Anthony, 1993; ÀRIES, Philippe, 1981.

${ }^{47}$ GIDDENS, 1993.

${ }^{48}$ BAUMAN, Zygmunt, 2004.

491993.

${ }^{50} 2004$. vida da gente que amar somente ao outro não basta (Ester).

[...] já não amo como aos 15, nem como aos 20, aos 30 eu tinha certeza que sabia o que era amor, e estava errada... hehehe... aos 40, peraí! Primeiro eu, depois os gatos de olhos azuis aqui... vale a pena estar longe de Fortaleza, pela cidade sim, viu, mas pela família, todo dia penso, me surpreenda Holanda e vou gostando do que tenho vivido! Mas aos 50, é muita coragem (Teresa, 40 anos).

Maria também expõe que entende que o amor pode ser construído, o que também se opõe aos ideais do amor romântico, em que os parceiros ideais, ou almas gêmeas, se encontram e se completam. Ela cita o romance dos protagonistas de uma novela brasileira da Rede Globo. Maya, indiana, foi obrigada a se casar com um homem que não amava e, no final da novela, confessou que aprendera a amá-lo: "vocês lembram da novela Caminho das Índias, onde a Maya (Juliana Paes) construiu um amor? Hoje em dia vivencio e comungo com esta filosofia..." (Maria).

Entendo o amor como prática social, ${ }^{42}$ não universal, cujos sentidos são variáveis de acordo com o tempo, espaço e contexto sociocultural. ${ }^{43}$ Os discursos de minhas interlocutoras são contrários a algumas afirmações que sustentam a importância do amor, que, para Jurandir Freire Costa, ${ }^{44}$ é um sentimento surdo à voz da razão e é um sentimento sine qua non da máxima felicidade a que os indivíduos podem aspirar.

O amor romântico seria parte de uma ideologia que surgiu no século XIX, quando a escolha do parceiro deixa de ser feita pelas famílias e o casamento começa a ser visto como uma forma de realização pessoal. ${ }^{45}$ Estaria relacionado, entre outras mudanças sociais e econômicas, à subordinação das mulheres aos lares e à invenção da maternidade enquanto valor social. Neste sentido, as mulheres passaram a ter maior controle sobre os filhos e as crianças começaram a ser percebidas como seres vulneráveis, que necessitam de cuidado e educação a longo prazo. ${ }^{46}$

As ideias que as sujeitas de minha pesquisa expressam sobre o amor estariam mais coerentes com os conceitos de amor confluente ${ }^{47}$ e amor líquido. ${ }^{48}$ Para Anthony Giddens, ${ }^{49}$ o amor confluente seria resultado da emancipação e maior autonomia sexual das mulheres. Trata-se de um sentimento que exige igualdade na doação e no recebimento emocionais entre os parceiros. Diferentemente do amor romântico, não é único nem eterno, mas ativo e contingente. Já Zygmunt Bauman $^{50}$ expõe que o amor líquido é próprio da instabilidade da pós-modernidade. Amar torna-se uma habilidade que se pode adquirir, cujo domínio aumenta com a prática. Equiparado ao consumo, o amor, assim como uma mercadoria, pode 
${ }^{51}$ BADINTER, Elisabeth, 1985.

${ }^{52}$ CHODOROW, Nancy, 1980. ser descartado, e serve para a satisfação de um desejo. Sua continuidade é constantemente avaliada em decorrência de seus lucros, pois, a exemplo de um mercado de ações, o amor é um investimento.

Apesar das ideias de que amor pode ser construído, é finito e não é suficiente para decidir migrar para a Holanda, as interlocutoras apontam para o único amor que, para elas, seria superior: o amor materno. "Acima de tudo, é o amor materno", disse Monica, completando que este amor deveria ser maior que o amor a si mesmo. São noções que apontam para as construções sociais da maternidade e do amor materno, ${ }^{51}$ que coexistem com ideias que estão mais relacionadas ao amor confluente e líquido do que ao amor romântico. A construção social da maternidade, que foi acompanhada por uma idealização da figura da mãe, emergiu como valor aliada a um novo modelo de família - a família nuclear burguesa, base social do capitalismo. ${ }^{52}$

\section{Considerações finais}

Mulheres e homens que se envolvem em relacionamentos ou casamentos binacionais estão longe dos estereótipos do senso comum. Não apenas mulheres jovens e pobres procuram homens europeus dispostos a retirá-las de países do Terceiro Mundo por meio de um relacionamento afetivo. As interlocutoras de minha pesquisa eram provenientes de diferentes localidades e classes sociais do Brasil, e contaramme ter refletido sobre as vantagens e desvantagens em se mudar para a Holanda para viver com o namorado. O artigo procura mostrar que essas avaliações tendem a se diferenciar de acordo com a etapa da vida de cada indivíduo. Desse modo, não apenas a idade é importante, como também outros marcadores que, no passado, serviam para delimitar os estágios da vida. Ter (ou não) filhos é um fator importante para avaliar os riscos em migrar para outro país. São decisões fortemente influenciadas pelas relações intergeracionais e de gênero. Neste sentido, a idade dos filhos e o nascimento dos netos podem liberar ou reinserir a mãe ou avó nas tarefas de cuidado dos membros da família.

O artigo também mostrou que as interlocutoras da pesquisa apresentam diferentes noções de amor ao longo de seu curso de vida. Se o amor romântico é mais apropriado aos vinte anos, após os quarenta ou cinquenta anos, este sentimento, tomado enquanto prática social, é mais próximo das noções de amor confluente ou líquido. Ainda assim, não são superiores ao amor da mãe pelos filhos. Podemos pensar, portanto, que, se queremos denominar essas mulheres de "migrantes por amor", devemos perguntar a quem este amor se destina. 


\section{Referências}

ARIÉS, Philippe. História social da criança e da família. Rio de Janeiro: LTC, 1981.

ATTIAS-DONFUT, Claudine. Les solidarités entre les générations. Vieillesse, famille, état Nathan. Essais et recherche. Paris, 1995.

Générations et âges de la vie. PUF, 1991.

AZEVEDO, Thales de. As regras do namoro à antiga. São Paulo: Ática, 1986.

BADINTER, Elisabeth. Um amor conquistado: o mito do amor materno. 2. ed. Rio de Janeiro: Nova Fronteira, 1985.

BAUMAN, Zygmunt. Amor líquido: sobre a fragilidade dos laços humanos. Rio de Janeiro: Jorge Zahar, 2004.

BEALL, Anne E.; STERNBERG, Robert J. The social construction of love. Journal of Social and Personal Relationships, n.12, p. 417-438, 1995.

BLANCHETTE, Thaddeus G. "Is it a real marriage?": imigração e casamentos entre brasileiros e anglo-americanos. In: PÓVOA NETO, H. e FERREIRA, A. P. (Orgs.). Cruzando fronteiras disciplinares: um panorama dos estudos migratórios. Rio de Janeiro: Revan, 2005, p. 133-151.

BOURDIEU, Pierre. Esquisse d'une théorie de la pratique, précedé de troisétudes d'ethnologie kabyle. Genève: Librairie Droz, 1972.

. La Jeunesse n'est qu'unmot. Entretien avec Anne-Marie Métaillé. In: Editions de Minuit, 1994.

BOYD, Monica. Family and personal networks in international migration: recent developments and new agenda. International Migration Review, 1989, v. 23, n. 3, p. 638670.

BOZON, Michel. A nova normatividade das condutas sexuais ou a dificuldade de dar coerência às experiências íntimas. In: HEILBORN, M. L. (Org.). Família e sexualidade. Rio de Janeiro: FGV, 2004a, p.119-150.

Sociologia da sexualidade. Rio de Janeiro: FGV, $2004 b$.

BRUQUETAS-CALLEJO, Maria; GARCÉS-MASCAREÑAS, Blanca; PENNINX, Rinus; SCHOLTEN, Peter. IMISCOE Working Paper: Country Report Policy making related to immigration integration. The Dutch Case. IMISCOE Working Paper: Country Report, Working Paper, n. 15, 2009. Disponível em: <http:/ /www.imiscoe.org/publications/workingpapers/ documents/IntegrationPolicymakingDutchcase.pdf $>$. Acesso em: 31 jul. 2015.

CHAUFFAUT, Delphine. L'évolution des relations entre générations dans un contexte de mutation du cycle de vie. Paris: CREDOC, 2001. 
CHODOROW, Nancy. Maternidade, dominación masculina y capitalismo. El Patriarcado capitalista y el feminismo socialista. Buenos Aires: Siglo Veintiuno, 1980.

CONSTABLE, Nicole (Org.). Cross-border marriages: gender and mobility in transnational Asia. Philadelphia: Pennsylvania University Press, 1998.

Romance on a Global Stage. Berkeley: University of California Press, 2003.

DEBERT, Guita Grin. A dissolução da vida adulta e a juventude como valor. Horiz. antropol. [online], v. 16, n. 34, 2010 [citado 2012-08-20], p. 49-70.

COSTA, Jurandir Freire. Sem fraude, nem favor: sobre o amor romântico. Rio de Janeiro: Rocco, 1998.

FOCUS MIGRATION. Netherlands. Disponível em: <http://focusmigration.hwwi.de/The-Netherlands.2644.0.html? L=1>. Acesso em: 31 jul. 2015.

GIDDENS, Anthony. A transformação da intimidade: sexualidade, amor \& erotismo nas sociedades modernas. 2.ed. São Paulo: UNESP, 1993.

GOODE, William J. The theoretical importance of love. American Sociological Review, 1959.

GREGORIO GIL, Carmen. Procesos migratorios y desigualdad de género, cuestiones de género en el fenómeno de las migraciones. Madrid: Univ. Pontifica Comillas, 2002, p. 11-38.

MANDERSON, Lenore; JOLLY, Margaret. Sites of desire/Economies of pleasure: sexualities in Asia and the Pacific. Chicago, Londres: The University of Chicago Press, 1997.

LUHMAN, Niklas. O amor como paixão. Para a codificação da intimidade. Lisboa: Difel, 1991.

MASSEY, Doreen. Space, placeand gender. Minneapolis: University of Minnesota Press, 1994.

MOTTA, Alda Britto. As dimensões de gênero e classe social na análise do envelhecimento. Cadernos Pagu, 1999, n. 13, p. 191-221.

PAIS, José Machado. A juventude como fase de vida: dos ritos de passagem aos ritos de impasse. Saude soc. [online], 2009 , v. 18, n. 3, p. 371-381.

PESSAR, Patrícia; MAHLER Sarah. Gender and transnational migration. The Center of Migration and Development. University of Princenton, 2001.

PFLUGFELDER, G. M. Cartographies of desire: male-male sexuality in japanese discourse, 1600-1950. London: University of California Press, 1999.

PISCITELLI, Adriana. Amor, apego e interesse: trocas sexuais, econômicas e afetivas em cenários transnacionais. In: PISCITELLI, A., ASSIS, G. O.; OLIVAR, M. (Orgs.). Gênero, sexo, amor e dinheiro: mobilidades transnacionais envolvendo o Brasil. Campinas: Unicamp/Pagu, 201 1, p. 537-582. 
Geografia política do afeto: interesse, "amor" e migração. Atas do $1^{\circ}$ Seminário de Estudos sobre Imigração Brasileira na Europa. Barcelona, 2010, p. 14-22.

RITIINER, Maria Eduarda Noura. A experiência dos casamentos interculturais: as mulheres culturalmente transplantadas. Atas do $1^{\circ}$ Seminário de Estudos sobre Imigração Brasileira na Europa. Barcelona, 2010, p. 65-72.

ROCA GIRONA, J. Migrantes por amor: la búsqueda y formación de parejas transnacionales. AIBR. Revista de Antropología Iberoamericana, v. 2, n. 3, Madrid, Antropólogos Iberoamericanos en Red, p. 430-458, 2007.

La excepción reveladora: esposas brasileñas de uniones mixtas en España, Suiza, Italia y Portugal. Atas do $1^{\circ}$ Seminário de Estudos sobre Imigração Brasileira na Europa. Barcelona, 2010, p. 73-80.

ROCA GIRONA, J. et al. Amor importado, migrantes por amor: la constitución de parejas entre españoles y mujeres de América Latina y de Europa del este en el marco de la transformación actual del sistema de género en España, 2009. Disponível em: <http://www.inmujer.migualdad.es/ mujer/mujeres/estud_inves/766.pdf $>$.

ROSALDO, M.; LAMPHERE, L. (Orgs.). Women, culture and society. Stanford: Stanford University Press, 1974.

SANTOS, Marta. Les constructions des stratégies conjugales et familiales des couples franco-bresiliens. Tese (Doutorado em Ciências Sociais e Filosofia do Conhecimento). L'Université Paris-Sorbonne, Paris, 2012a.

SCHAEFFER-GRABIEL, F. Cyber brides and global imaginaries: mexican women's turn from the national to the foreign. Space \& Culture, 2004, v. 7, n. 1, p. 33-48.

SCOT, Russell Parry. Quase adulta, quase velha: por que antecipar as fases do ciclo vital? In: SILVA, Maria Dulce; NERY, Inez Sampaio (Orgs.). Cenários e personagens plurais. Teresina: REDOR/NEPEM/UFPI, 2009, p. 207-217.

THAl, Hung Cam. Clashing dreams: highly educated overseas brides and low wage U.S. husbands. In: EHRENREICH, B.; HOCHSCHILD, A. R. (Orgs.). Global woman, nannies, maids and sex workers in the new economy. New York: Owl Books, 2002, p. 230-254.

THAl, H. C. For better or worse: vietnamese international marriage in the new global economy. New Brusnwick: Rutgers University Press, 2008.

TOGNI, Paula. Os fluxos matrimoniais transnacionais entre brasileiras e portugueses: género e imigração. Dissertação (Mestrado), Instituto Superior de Ciências do Trabalho e Empresa (ISCTE), Departamento de Antropologia, Lisboa, 2008.

WILLIAMS, Lucy. Global marriages: cross-border marriage migra-tion in global context. Hampshire (UK), New York: Palgrave Macmillan, 2010. 
WOORTMANN, Klaas. A etnologia (quase) esquecida de Bourdieu, ou o que fazer com heresias. Revista Brasileira de Ciências Sociais, 2004, v. 19, n. 56, p. 129-137.

YOUNG, Robert J. C. Desejo colonial: hibridismo em teoria, cultura e raça. São Paulo: Perspectiva, 2005.

[Recebido em 11 de março de 2014 e aceito para publicação em 31 de julho de 2015]

Agradeço à Capes pela bolsa de pós-doutorado que possibilitou a presente pesquisa.

\begin{abstract}
Migrants for Love? Life Course, Gender and the Decision of Migrating at Different Stages of Life

Abstract: This article shows the importance of the life course, intertwined with gender perspective to analyze the processes of decision-making of Brazilian women about migrate (or not) to the Netherlands to live with their Dutch partners. According to interlocutors of ethnographic research conducted between 2012 and 2013, age is an important factor to be considered to analyse the risks, advantages and disadvantages of migration. Besides age, other markers of life course, like having children, the birth of grandchildren and the children age are also considered in their decision-making processes. The article also provides the considerations of the interlocutors of research on love, which, according to them, differs at every stage of life. More than love for the Dutch boyfriend or husband, they emphasize and reify the idealization of maternal love.

Key words: Migration; Intercultural marriages; Life course; Age; Gender.
\end{abstract}

